\title{
Assessment criteria for decisions in the field of rail freight transportation
}

\author{
Iuliia Tanaino, ${ }^{1,}$, Olga Yugrina $^{1}$, and Larisa Zharikova $^{1}$ \\ ${ }^{1}$ Siberian Transport University, 630049 Novosibirsk, Russia
}

\begin{abstract}
Timely relocation of empty cars to loading stations plays an important role in rail freight transport logistics. The purpose of the study is to determine the criteria for identifying a need for reserved station tracks while minimizing operating costs. The authors used special methods to study freight transport operations and mathematically modeled the transportation process subject to the developed technological measures, such as concentrating the car traffic at stations and yards with sufficient technical capabilities, minimizing the number of handling operations in transit, and differentiating cars according to their respective operators. As a result, the authors identified the criteria underlying the decision-making algorithm for managing rail transport operations, while minimizing costs throughout the service area.
\end{abstract}

\section{Introduction}

Technical regulation of rail transport operations is a way of managing the entire transportation process that helps to achieve optimal distribution of vehicles. Standard indicators of car fleet utilization are determined through a technical regulation process. The efficiency of transport operations management is determined by estimating utilization indicators for locomotive and car fleets. However, in the context of the ongoing privatization of car fleets in Russia, only two criteria can be used to assess the quality of rail transport operations: speed and transit time of cars.

Reliable technical standards, such as objective criteria for transport operations, contribute to the development of sustainable solutions in planning of rail transport operations. These solutions, in turn, contribute to increasing the stability of car traffic and providing loading operations with necessary facilities. Operations with empty cars are significantly streamlined. The current methods for technical regulation of quantitative and qualitative indicators have a number of shortcomings. Such qualitative indicators as service speed, waiting times for transit and local cars at stations and yards, and waiting times for cars per cargo operation, are determined without taking into account their dependence on traffic volume and utilization rate of the infrastructure. Due to shortcomings in the current technical regulation system, operational management methods come to the fore. This approach has a negative impact on the entire transportation process [1-3].

\footnotetext{
*Corresponding author: chechulinau@gmail.com
} 
From the above, it can be concluded that efficient car traffic management, especially for empty cars, with cost minimization is an important problem for freight transportation and sustainable use of the railway infrastructure. At present, the technology has fundamentally changed in the context of private fleets of empty cars. This has led to a higher utilization rate of the infrastructure and changed the interaction between carriers and owners of rolling stock. There are no effective measures in place to optimize this process [4-12].

In other countries, rail freight logistics faces a strong competition from other modes of transport. In this context, operators need to focus primarily on interests of cargo owners and plan just-in-time deliveries by following a train schedule with maximum routing $[13,14]$. The following methods are used: an individual approach to delivery times; reducing the total handling time of cars at stations and yards; increasing the weight of freight trains (if this measure can reduce operating costs); door-to-door delivery services; separating a core of freight trains with accelerated turnaround in a schedule $[15,16]$. In Russia, due to long distances (more than six thousand $\mathrm{km}$ ), rail transport operations create a significant load on the infrastructure: the utilization rate is 2.7 times higher than that in other countries. However, the fact that the railway infrastructure belongs to a single owner allows minimal reserves and costs to be managed [17].

Thus, it is important to study this problem since its solution will increase the competitiveness of railways by allowing carriers and owners of car fleets to reduce the delivery time, develop regulations for empty cars adapted to the new conditions and, therefore, minimize their operating costs. The subject of the study is logistics principles for empty private cars that take into account the freight transport technology and operating costs of rail transport. The purpose of the study is to refine the criteria for identifying a need for reserved station and yard tracks while minimizing operating costs. These criteria will make it possible to comprehensively assess feasible utilization of capacities of railway sections based on available infrastructure and traction facilities, and to identify priorities in development of the rail freight transport technology. The paper proposes an algorithm based on the refined criteria to perform an integrated assessment of infrastructure capabilities and select options of station infrastructure utilization by redistributing classification operations among railway stations and yards.

\section{Research methods}

In order to determine optimization measures in transportation of empty private cars, the authors analyzed operations with cars during the delivery using special methods for studying freight operations. Taking into account the railway transport technology, they developed a transportation flow chart with constituent elements and time inputs [18]. It has been established that there are some difficulties in operating empty cars in cooperation with rolling stock operators:

1) due to excessive saturation of stations and yards with cars, some of their tracks remain inactive. This reduces traffic and handling capacities of stations and yards;

2) due to oversaturation of sections with trains, part of trains are left at wayside stations without locomotives, which reduces the number of tracks for crossing and passing trains and removes some train paths.

A relationship between station fleets, locomotives, freight traffic and service speed indicates that the maximum freight traffic volumes with maximum limits of park fleets increases the need for reserved tracks at stations and yards. Based on these relationships, it is possible to comprehensively estimate the feasible utilization of capacities of railway sections, taking into account the availability of infrastructure and traction facilities. They can be represented as a cause-and-effect loop (Fig. 1). In order to break this loop and overcome difficulties, it is necessary to fill a gap of track capacity by physically expanding 
the number of tracks (extensive method) or improving the technology that can replace the reserved track capacity with management reserves (intensive method).

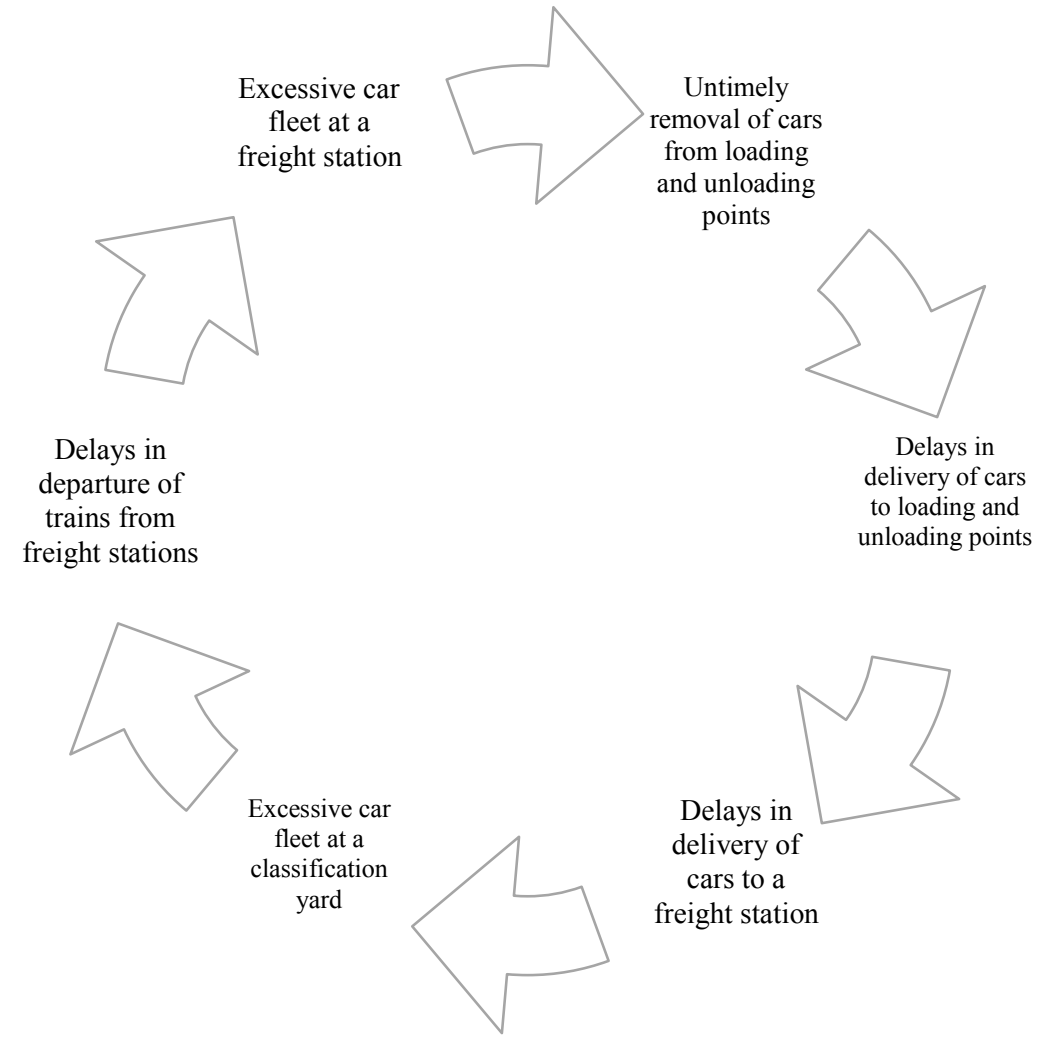

Fig. 1. Cause-and-effect loop.

By optimizing the technology (intensive method), it is possible to accelerate the car turnaround and increase a fleet of cars in a hold yard, i. e. the utilization of track capacity can be reduced while maintaining the same number of cars. One of the research methods used by the authors is mathematical modeling, which allows the system (in our case, the process of rail freight transportation) to be described in general terms and presented as a formula. Using this approach, the economic result for a carrier from the introduction of technological measures can be presented as a solution to the problem with the objective function of minimizing related operating costs for transportation:

$$
E_{e c}=\sum E=E_{t r}+E_{\text {nothandled }}+E_{\text {handled }}+E_{\text {load }} \rightarrow \min
$$

where $E_{t r}$ are the operating costs for transportation of cars in trains in railway sections; $E_{\text {nothandled }}, E_{\text {handled }}$ are the operating costs incurred by a carrier when cars remain idle at technical stations without and with handling, respectively; $E_{\text {load }}$ are the operating costs incurred by a carrier when cars are idle at loading/unloading stations.

The solution to this function depends on how efficiently the following criteria are implemented in practice: trains follow the shortest path with the minimum possible number 
of car handling operations, subject to rated limits of classification yards; the car traffic is differentiated by type of cargo, type of rolling stock, and owner.

As noted by leading scientists [18], one of the decisive technological measures is to manage transportation of empty gondola cars by various types of route trains. Due to uneven intake of cars and loading, rolling stock operators need a reserve of cars. Instead of keeping necessary reserves, it is possible to manage the intake of empty cars.

It has been found that reserves are not created in static conditions (waiting times at marshaling yards increase). By creating routes for breaking up trains, we can quickly manage the intake of empty cars, taking into account a departure sequence of trains for loading stations.

Trains are made up from empty cars: (1) on non-public railways; (2) at large unloading stations; (3) at classification yards and section stations from cars coming from other stations.

Possible making-up options:

1) through trains from empty cars of a certain fleet involved by a carrier are made up at technical stations and bulk unloading stations, and then delivered to a loading station according to a loading order.

2) designation of trains from empty cars, including:

- through trains from empty cars of any origin to certain destination stations,

- direct technical routes of trains from empty cars in loading stations or hold yards belonging to certain rolling stock operators or their associations,

- technical routes for breaking up,

- forwarder routes of trains from empty cars of certain rolling stock operators from unloading stations, relocation stations or hold yards.

The study of the existing car traffic structure has revealed that empty cars, including gondola cars, are delivered to a loading station with a considerable number of handling operations at classification yards and technical stations in transit. In order to reduce the number of these handling operations, it is necessary to concentrate a selection of empty gondola cars at a smaller number of stations, taking into account their location throughout the service area. It is reasonable to use the stations and yards located at the entrance to a coal loading region to create technical routes in a number of directions. By using better equipped yards, it is possible to use classification facilities to a fuller extent and reduce operating costs for rail transportation of goods. A comparison can be based on information on operating processes in stations and yards. Their performance parameters and time inputs that determine the utilization of stations and yards should be kept up-to-date. Capabilities of classification yards and systems are limited to allowable handling volumes according to a making-up plan and train schedule. In other words, technical capabilities of classification yards are one of the criteria that influence the choice of a car traffic management option for the service area.

\section{Results}

Thus, in order to increase the transit traffic of cars, it is necessary to consider various routing options. A choice of transport operations management options should be based on the criteria that make it possible to minimize costs throughout the service area. The decision-making algorithm for transport operations management includes the following steps:

1) At first, feasibility of delivering goods with the shortest possible routes should be studied. Choice of routes that are not the shortest ones may be reasonable if they are associated with a lower cost of passing trains (use of parallel tracks with better performance parameters, such as type of traction, throughput capacity, possibility of passing heavier 
trains without weight reduction). If the capacity of sections is sufficient, it is reasonable to select a route with minimal operating costs:

$$
E_{t r} \rightarrow \min
$$

2) Geographical location of handling stations: the possibility of concentrating car traffic and combining directions at entry and exit of handling stations. Otherwise, there is a need for additional handling operations at trailing stations, and a train fails to follow the shortest possible route. A possibility of reducing the number of handling operations in transit and excluding backhaul of cars is considered:

$$
E_{\text {tr }}+E_{\text {handled }} \rightarrow \min
$$

3) Mandatory inspection of technical capabilities (rated limits) involved in car handing. Excessive traffic will require some operational measures, which always increase costs. Technical capabilities of car handing stations are considered subject to the number of destinations:

$$
E_{\text {handled }} \rightarrow \min
$$

4) Minimization of handling operations in transit. This measure will reduce car turnaround and minimize costs by reducing a load on the infrastructure and a required fleet of cars to be maintained by car owners. An increase in the transit traffic, achieved through en-route transportation and reduction of car handling operations, is taken into account as well:

$$
E_{\text {handled }} \rightarrow \min
$$

5) At present, it is reasonable to differentiate the traffic of loaded and empty cars. The traffic of loaded cars should be analyzed taking into account types of goods transported, such as coal or oil products. When analyzing the traffic of empty cars, it is reasonable to consider type of rolling stock. This approach makes it possible to differentiate the car traffic according to the characteristics mentioned above and designate different types of traffic to specific stations, thereby reducing handling operations at destination stations. It is also necessary to consider preparing trains for loading stations (empty cars) and unloading stations (loaded cars) at large classification yards subject to customer requirements. This will reduce costs of operations at freight stations, since marshalling operations at hump yards are cheaper:

$$
E_{\text {load }} \rightarrow \min
$$

6) Taking into account that cars belong to different owners or lessees, there should be a possibility of making up trains from empty cars of certain types and certain rolling stock operators at specially designated classification yards. For large operators, the concentration of empty cars at certain yards speeds up the delivery of cars and allows operators to accurately predict the time of arrival for loading, without burdening infrastructures of destination stations. Moreover, this approach makes it possible to plan a sequence in which empty cars are delivered to several stations in a region of loading. It also allows loading stations to satisfy their needs for cars of specific operators according to customer requests, thereby reducing costs of operations at freight stations due to a lower cost of marshalling at hump yards: 


$$
E_{\text {handled }}+E_{\text {load }} \rightarrow \min
$$

By implementing the transportation process in accordance with the rail transport technology, it is possible to predict the delivery time with a sufficient degree of accuracy [19]. By reducing the turnaround of a freight car on an empty leg and predicting delivery time, rolling stock operators will reduce their costs for maintaining a reserve of cars, which is required due to uneven intake and loading:

$$
E_{\text {operators }}=\Delta n \cdot C_{c a r} \rightarrow \min
$$

where $\Delta n$ is the change in the active car fleet from the introduction of technological measures; $C_{c a r}$ is the unit cost per car used by a rolling stock operator.

Based on the Siberian and Far Eastern Federal districts of the Russian Federation, the authors considered redeploying classification operations to a yard $\mathrm{T}$, in which empty cars are differentiated by owner and direction. It is difficult to create loop routes for empty gondola cars at port railway stations due to their remoteness. By introducing technical routes to the classification yard $\mathrm{T}$ for breaking up, operators will avoid unnecessary handling in their service area. By making up trains from empty gondola cars at the same yard, they will avoid unnecessary handling in transit.

If a rolling stock operator is interested, cars can be sent to the yard $\mathrm{T}$ for loading only from stations of individual railways. In this case, the operator can reduce the car turnaround on an empty leg and the delivery time of cars, and, most importantly, implement the just-intime delivery principle that allows it to determine the transit time with sufficient accuracy. Therefore, while introducing technical routes, operators should conclude contracts to standardize the delivery time, taking into account the rail freight transport technology. By taking the just-in-time approach to the proposed en-route deliveries, operators will reduce the car turnaround and free up 1,045 cars/day. This, in turn, will reduce a load on their infrastructures by freeing up tracks of the classification yards listed above and open-line tracks.

\section{Conclusion}

The developed criteria for selecting car traffic management options, which allow operating costs to be minimized throughout the service area, make it possible to optimize railway transport operations. This will make it possible to efficiently use tracks of stations and yards, as well as reduce the required rolling stock and minimize costs for railway infrastructure development. In order to efficiently manage the traffic of empty cars, it is necessary to prioritize the making-up process on non-public tracks or tracks of unloading stations and classification yards in transit. By reducing the car turnaround and predicting the delivery time of cars to a point of destination, operators can significantly facilitate their activities. Therefore, it is reasonable to identify incentive measures for creating different types of routes from empty cars after unloading of bulk goods. Further research by the authors will be aimed at developing a criterion for minimizing operating costs by reducing the number of car handling operations in transit.

\section{References}

1. Instructions on the organization of railroad car flows on the railways of Russian Railways JSC, 16.10.06 (2007). (in Russian) 
2. A.F. Borodin, Trudy VNIIAS, 6 (2008). (in Russian)

3. K.P. Shenfeld, Doctoral thesis, Moscow State University of Railway Engineering, Moscow, 2014. (in Russian)

4. O.P. Yugrina, Zheleznodorozhnyj transport [Railway transport], 10, 25-30 (2010). (in Russian)

5. A.F. Borodin, Bjulleten' Objedinennogo uchenogo soveta OAO RZhD [Bulletin of the Joint Scientific Council of Russian Railways JSC], 2, 65-73 (2017). (in Russian)

6. O.P. Yugrina, Nauchnye problemy transporta Sibiri i Dal'nego Vostoka [Scientific transport problems in Siberia and the Far East], 4, 14-17 (2015). (in Russian)

7. S.Yu. Eliseev, Zheleznodorozhnyj transport [Railway transport], 10, 30-33 (2015). (in Russian)

8. A.F. Borodin, Mir transporta [World of Transport and Transportation Journal], 1(68), 6-17 (2017). (in Russian)

9. V.G. Lemeshko, V.A. Sharov, Zheleznodorozhnyj transport [Railway transport], 11, 12-20 (2010). (in Russian)

10. N.P. Shipulin, Zheleznodorozhnyj transport [Railway transport], 2, 52-55 (2012). (in Russian)

11. Yu.A. Chechulina, Nauchnye problemy transporta Sibiri i Dal'nego Vostoka [Scientific transport problems in Siberia and the Far East], 2, 92-95 (2013). (in Russian)

12. V.A. Sharov, Zheleznodorozhnyj transport [Railway transport], 3, 33-35 (2017). (in Russian)

13. M. Bielli, A. Bielli, R. Rossi, Procedia Social and Behavioral Sciences, Vol. 20, 4-18 (2011).

14. M. Demers, Saving Time, Saving Dollars (2014), available at: https://wasteadvantagemag.com/saving-time-saving-dollars

15. P. Zhang, Journal of Railway Engineering Society, 32(6), 81-86 (2015).

16. T. Mai, E. Frejinger, M. Fosgerau, Transportation Research. Part B: Methodological, 75, 100-112 (2015).

17. P.V. Kurenkov, F.I. Khusainov, A.A. Sechkarev, Vestnik transporta, 4, 10-16 (2014). (in Russian)

18. V.V. Panin, E.S. Prokofyeva, D.V. Rubtsov, Bjulleten' Objedinennogo uchenogo soveta OAO RZhD [Bulletin of the Joint Scientific Council of Russian Railways JSC], 2, 57-64 (2017). (in Russian)

19. L.S. Kazantseva, Nauchnye problemy transporta Sibiri i Dal'nego Vostoka [Scientific transport problems in Siberia and the Far East], 2, 39-43 (2013). (in Russian) 